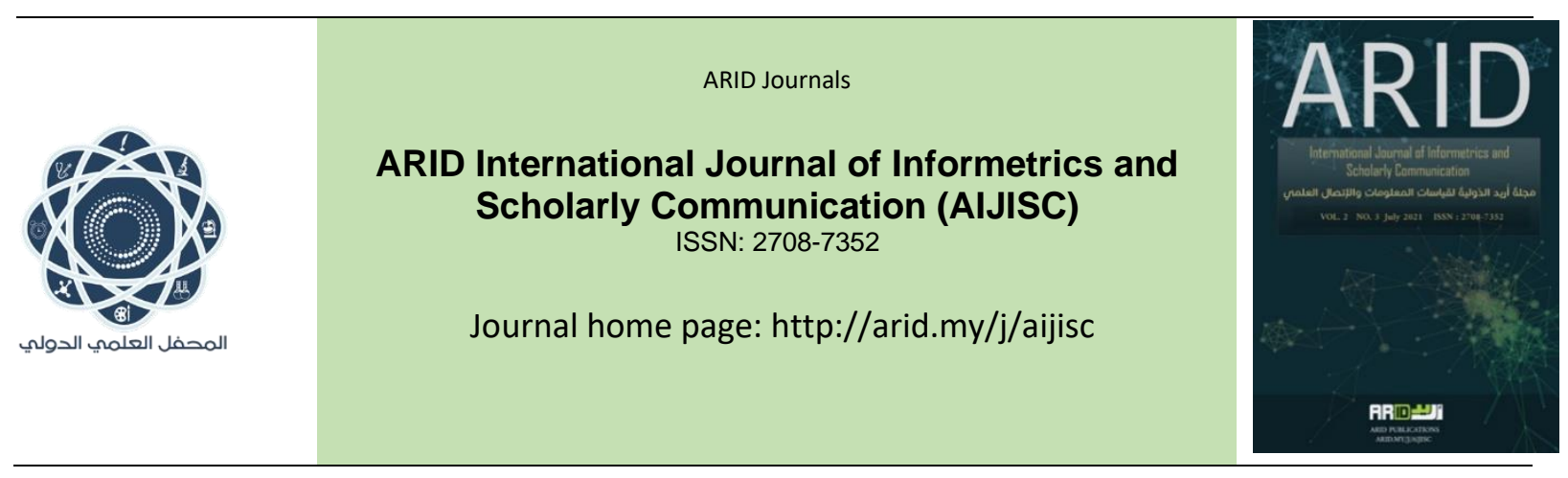

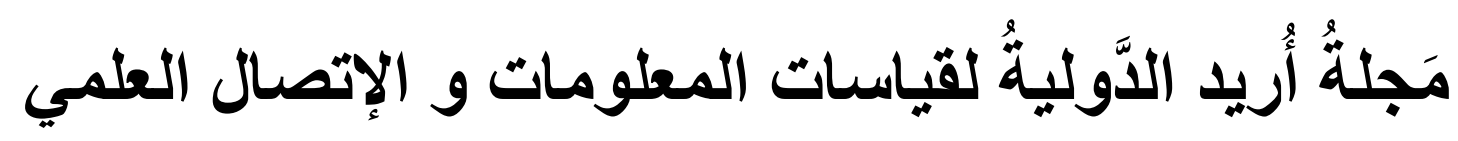 العدد 3 ، المجلد 2 ، تموز 2021 م
}

\section{ARID Platform after Five Years of Its Establishment (2016-2021):}

\section{A bibliometric Study}

Maryam Qays*1, Saif Yousif ${ }^{2}$, Abdelrahman Farrag ${ }^{3}$ Sherif Kamel Shahein ${ }^{4}$

1- Faculty of Engineering and Built Environment, UKM university, Selangor, Malaysia

2- Faculty of Dentistry, University Of Malaya, Selangor, Malaysia

3- Information Sciences Department, Beni-Suef University, Egypt

4- Department of Libraries ,Documents and Information Science - Cairo University

$$
\begin{aligned}
& \text { منصة أُريد بعد أربع سنوات من تأسيسها (2016-2016) : } \\
& \text { دراسة ببليومترية } \\
& \text { مريم قيس 1"، سيف السويدي²، عبدالرحمن فراج3، شريف كامل شاهين4 } \\
& \text { 1- كلية الهنسة و بيئة المباني - الجامعة الوطنية الماليزية- سلانجور - ماليزيا } \\
& 2 \text { - كلية طب الاسنان - جامعة ملايا- كو الالمبور - ماليزيا } \\
& \text { 3- قسم المعلومات - كلية الآداب - جامعة بني سويف ـ مصر }
\end{aligned}
$$

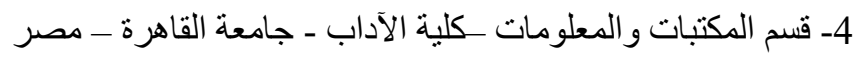

aiji@arid.my

arid.my/0001-1034

https://doi.org/10.36772/arid.aijisc.2021.231 


\begin{tabular}{l}
\hline A R T I LE INFO \\
\hline Article history: \\
Received 20/05/2021 \\
Received in revised form 1/06/2021 \\
Accepted 20/06/2021 \\
Available online 15/07/2021 \\
\hline
\end{tabular}

\begin{abstract}
After five years of the official opening of ARID (Arabic Researcher ID) platform, the number of its users exceeded 70 thousand who can speak Arabic from all over the world. ARID platform is the first Arabic platform to serve scientific research in a way that keeps pace with technical development, which made the access to the scientific research available to all users. The study aims to introduce ARID platform using numerical indicators to transmit a statistical picture for the scientists, experts and researchers on the first digital platform for Arabic speakers and how to make full use of this experience and data analysis in other digital platforms that serve the Arabic language. The study used the descriptive analytical method, and some methods of bibliographic measurements. The information was extracted from ARID platform database on $12^{\text {th }}$ of May 2021, and transferred to Excel to facilitate data analysis. The study concluded several results, however, the most important of which is that the number of users on ARID platform is increasing dramatically, and their numbers vary in different countries and universities. The platform included a wide range of various disciplines, most notably the specializations of educational sciences, sciences, arts, and political sciences, with a large number of holders of higher degrees (masters and doctorate), as they exceeded eleven thousand users. Participation in conferences is on the top of the list of academic activities, followed by the participation in scientific courses. Meanwhile, the number of scientific publications on the platform exceeded 16 thousand, and on top of them were the articles that published in scientific journals, where the number exceeded ten thousand research papers. In addition, 36 types of academic activities have been keyed
\end{abstract}


in, including publishing books and participating in conferences and seminars. In conclusion, the researchers recommended that the awareness of joining the platform should be spread among Arabicspeaking researchers in all countries of the world to preserve the Arab identity, share scientific interests, and enrich Arabic content with scientific research. Based on these results, a number of recommendations were presented, including the need to target minimal ARID members registered disciplines, and to encourage similar disciplines to join the platform, as well as encouraging researchers from the minimal ARID registered countries to join the platform.

Keywords: ARID Platform, Bibliometrics, scientific platforms, Scholarly communication, online education. 


\section{الملخص}

مع تتامي أعداد المستخدمين في منصة أُريد، و الذي تجاوز (70) ألف مستخدم ناطق باللغة العربية من مختلف دول العالم بعد خمس سنو ات من تأسيسها. وتعدّ "أُريد" أول منصة رقمية عربية تخدم البحث العلمي بطريقة مو اكبة للتطور التقني مما جعل من الوصول للأبحاث العلمية في متناول الجميع. وتهدف الدر اسة إلى التعريف بمنصة أريد بلغة الأرقام لنقل صورة إحصائية للعلماءو الخبر اءو الباحثين عن المنصة وكيفية الاستفادة من هذه التجربة و تحليل المعطيات الموجودة في منصة رقمية تخدم اللغة العربية. وتعتمد الدر اسة على المنهج الوصفي التحليلي، وعلى بعض أساليب القياسات الور اقية (البيليوجر افية) بشكل أساسي. وقد تم استخر اج المعلومات اللازمة للدراسة من قاعدة بيانات "منصة أُريد" بتاريخ 12 مايو 2021، ثم تحويل النتائج إلى برنامج Excel لتسهيل تحليل البيانات. وقد توصلت الدراسة إلى نتائج عدة أهمها: إن أعداد المستخدمين في منصة أريد في ارتفاع مستمر، وتتفاوت أعدادهم بين مختلف الدول والجامعات، وأن المنصة تضم تجمعاً واسعاً من مختلف التخصصات أبرزها تخصصات العلوم التربوية والعلوم والآداب والعلوم السياسية، وتضم عدداً كبيراً من حملة الثهادات العليا (الماجستير و الدكتور اه)، إذ بلغ عددهم نحو (11) ألف مستخدم، وتتصدر المشاركة في المؤتمر ات قائمة الأنشطة الأكاديمبة، ثم تليها المشاركة في الدور ات العلمية، كما تجاوز عدد المنشور ات العلمية في المنصة (16) ألف منشور، وتأتي في مقدمتها المقالات المنشورة في المجلات العلمية حيث تجاوز عددها عشرة آلاف ورقة بحثية. ومن حيث الأنشطة الأكاديمية، فقد تم التوصل إلى (36) نمطًا من الأنشطة الأكاديمية من ضمنها: تأليف الكتب و المشاركة في المؤتمرات والندوات. ونوصي بضرورة نشر ثقافة الانضمام إلى المنصة بين الباحثين الناطقين باللغة العربية في جميع دول العالم للحفاظ على الهوية العلمية العربية و الارتقاء بالاهتمامات العلمية و إثر اء المحتوى العربي بالبحوث العلمية و لاسيما التخصصات البينية. واستناداً على هذه النتائج، فقد تم تقديم جملة من التوصيات منها ضرورة استهاف منتسبي التخصصات القليلة وتشجيعهم على الانضمام للمنصة وكذلك تشجيع الباحثين من الدول التي فيها أعداد الباحثين المنضمين للمنصة قليل نسبياً على الانضمام للمنصة.

الكلمات المفتاحية: منصة أريد، الدراسات البيليومنرية، القياسات البيليوجر افية، المنصات العلمية، الاتصال العلمي، التعليم عن بُعد. 


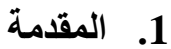

أصبحت المنصات العلمية والتعليمية وما توفره من خدمات جز ءاً من سمات المجتمعات العصرية بعد أن انتشر استخدام الحو اسيب و الهو اتف الذكية والثبكات بشكل كبير، حيث استطاع هذا التطور أن يغيُر مفهوم التعليم التقليدي الذي يتطلب تواجد المعلمين و المتعلمين في نفس المكان والزمان، كما استطاع توفير إمكانيات عديدة ومتنو عة. ويُعزى تطور التعليم الإلكتروني إلى عدة أسباب أهمها التطور في تقنيات الاتصالات و الحواسيب و الحاجة إلى اكتساب مهار ات جديدة دون تعطيل الحياة العملية للمتعلمين و الحاجة إلى تقليل كلفة التعليم. ولعل من أهم ما يمكن تحقيقه من خلال للتعليم الإلكتروني هو الوصول إلى أوسع نطاق ممكن من المستخدمين في أماكن متنوعة من العالم، والخروج من المحلية إلى العالمية، كما يتمتع بسهولة تطوير المحتوى المتاح على الإنترنت، بالإضافة إلى تفاعلية أدوات التعليم، وسهولة الوصول إلى المعلومات وما يتبع ذلك من توفير الوقت والجهد (جبور، 2020). وبصفة خاصة، أصبح استخدام التعليم الإلكتروني ضرورة مُلحة بعد انتشار وباء كورونا في بداية عام 2020 و إغلاق المدارس و الجامعات أبو ابها لتجنب الاختلاط وتقليل فرص انتشار الوباء (العر اقي، العتيبي، العصيمي، 2021)

ولكي يتم تجميع المو اد العلمية و العاملين بها من أساتذة وطلاب في بيئة عمل افتر اضية واحدة فقد تم إنشاء المنصات platforms و التي يمكن تعريفها إنها عبارة عن بيئة تعليمية تفاعلية توظف تقنية الويب وتجمع بين مميزات أنظمة إدارة المحتوى الإكتروني وبين شبكات التواصل الاجتماعيـ كالفيس بوك وتويتر - وتمكن المعلمين من نشر الدروس ووضع الواجبات وتطبيق الإنشطة التعليمية، والاتصـال بالمتعلمين من خلال تقنيات متعددة، تقسمه إلى مجموعات عمل، وتساعد على تبادل الأفكار (محمد،

وقد أدى تبني مفهوم الوصول الحرOpen Access مؤخر اً إلى نشر المنشور ات العلمية بحرية ودون قيود بعد أن كان الوصول إليها بيد دور النشر التجارية حيث يمكن تعريف الوصول الحر بأنه إطلاق الإنتاج الفكري و إتاحته على الإنترنت، والسماح لأي من المستفيدين بالاطلاع، و التحميل، و النسخ، و التوزيع، و الطباعة، والبحث، أو الربط بالنصوص الكاملة لتلك المقالات، وتتبعها بغرض التكثيف، ونقلها كبيانات إلى البرمجيات المتتو عة، أو الإفادة منها لأي غرض من الأغر اض (فر اج، 2017)

وتتنوع مكونات المنصات تنو عاً كبيرًا بتنوع وظائفها وفئاتها وجمهور المستفيدين منها (قيس، السويدي، فر اج، 2020). ويمكن القول إن من أهم خصائص المنصات العلمية هي إدارة المحتوى حيث يمكن إنشاء محتوى ثري و إدارنه إلكترونياً وتخزين ذلك 
المحتوى و التخطيط للمناهج و الدروس المقدمة. كما يمكن من خلال المنصة تقييم المتعلمين و إثشر اكهم في تطوير المحتوى حيث يلعب التقييم دوراً مهماً في العملية التعليمية لقياس مدى استجابة المتعلمين ومدى استفادتهم من المادة العلمية المقدمة. كما توفر المنصات التفاعلية بين المعلمين و المتعلمين باستخدام مستوى عالي من التكنولوجيا (جادالله، 2021).

وتقدم المنصات الرقمية، على اختلاف أشكالها وفئاتها، عديدًا من خدمات المعلومات مثل تحميل الملفات ونشرها وتقاسدها بين الأعضاء، و البحث عن المعلومات المحتو اة فيها؛ وذلك بهدف دعم أواصر التو اصل العلمي بين الباحثين، وتطوير النشاط العلمي في التخصصات الموضو عية المتنو عة. وقد ظهرت في الآونة الأخيرة بعض المنصات الرقمية التي تدعم الباحثين بشتى لغات العالم الحية ومن أشهر ها منصة Academia ResearchGate و وقد أدى افتقار الباحث الناطق بالعربية لمثل هذه المنصات إلى إنشاء منصة عربية علمية تُمكن الباحث العربي الحضور و التو اصل العلمي من خلالهاوتبادل المعلومات و الأفكار فما بينه وبين نظر ائه من الباحثني، وهي ما أُطلق عليها اسم منصة أُريد، وهي موضوع هذه الدراسة.

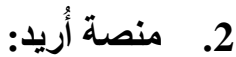

هي منصة علمية غير ربحية مسجلة في بريطانيا بإسم ARID SCIENTIFIC LTD. وقد تم افتتاحها يوم 25 أبريل 2016 كأول منصة رقمية للعلماء والخبر اء والباحثين الناطقين باللغة العربية، في جامعة الملايا في كو الالمبور - ماليزيا، وقد سبق تدشين المنصة در اسات مستفيضة عن المنصات العلمية ومدى الحاجة إلى منصة تخدم الباحث العربي بشكل يو اكب التطور التقني المتسارع فضلا عن النشاط العلمي المتنامي في العالم العربي في السنوات الأخبرة، وقد تم مناقتشة ذلك في ثلاثة ملتقيات علمية سبقت ذلك التششين. والهدف العام للمنصة هو جَمْعُ الباحثين الناطقين بالعربية في دَائرةٍ ِعِميةٍ واحِدة، حيث يساعد ذلك الباحثين أصحاب التخصصات المتشابهة و المتقاربة على التو اصل فيما بينهم ومتابعة بعضهم البعض لغرض مشاركة الاهتمامات العلمية، وتوفير فرصة عرض أعمالهم وسير هم الذاتية وجهودهم العلمية في صفحة شخصية خاصة، و إعطاء رقةٍ مُعَرٍِّ خاص بكلِّ باحثٍ لتجنب مشاكل تداخل وتشابه أسماء الباحثين مما قد يؤدي إلى ضياع حقوق الباحث (ماهي منصة أريد، 2016). كما تهدف المنصة إلى تعزيز حضور الباحثين الناطقين باللغة العربية في العالم الافتر اضي للمساهمة في تطوير البحث العلمي (سلمان، 2019)، و إعداد نظام تصنيف لكلِّ باحثٍ ومُؤسسةِ أكاديميةٍ على غِرار التصانيفِ العالميةِة المعتمدة. 
وتعد منصة أُريد شبكة اجتماعية أكاديمية، تخدم الباحثين الناطقين باللغة العربية، وتتيح مشاركة الأنشطة الأكاديمية مثل مشاركة الأور اق و البيانات وبالتالي فإنها تدعم سياسات الوصول الحر، حيث إن زيادة النسخ الإلكترونية للبحوث تساعد في زيادة إمكانية الاقتباسات لهذه البحوث كما كثفت عنه إحدى الدراسات ( \&brahimy, Mehrad, Setareh, \& .(Hosseinchari, 2016 إضافة إلى ذلك، يمكن للباحثين متابعة أقرانهم المتخصصين في المجال نفسه ومعرفة عدد متابعي صفحاتهر. كما أنها تتيح نشر أسئلة عامة على هذا التجمع الافتر اضي و إمكانية الإجابة عنها، وتمكن الجامعات من البحث عن أعضاء طاقم تدريسي جدد في كافة التخصصات. وقد تم مؤخر اً تفعيل معامل التو اصل العلمي C-Index ونقاط النشاط العلمي التو اصلي في منصة أُريد Score ARID، و يعتمد احتساب معامل التو اصل العلمي على عدة معايير منها

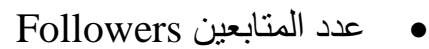

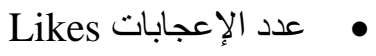

$$
\text { Posts المنشور ات }
$$

\section{Comments التعليقات المنميزة}

$$
\text { Badges الأوسمة }
$$

البحوث المنشورة بملفات كاملة Research Published

$$
\text { Certificates ع ع • ع الثهادات }
$$

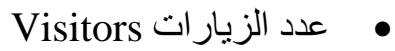

• عدد المسجلين عبر حساب الباحث في منصة أريد Registered Users، في حين تم اخفاء بعض المعايير الأخرى حفاظاً على جودة المعامل ـ ويعد هذا المعامل مهماً في تصنيف الباحثين و الجامعات وفقاً لمدى تو اصل الباحث، وقد تم استخدامه بداية في موسو عة منصة أُريد الصادرة في 2021 لتصنيف الباحثين، كما يمكن استخدامه لتصنيف وترتيب الجامعات وفقا للتو اصلية العلمية لكل جامعة (منصة أريد، 2021). 


\section{3. - أهداف الاراسة}

تهذف هذه الدر اسة إلى محاولة التعرف على بعض الخصائص البنيانية لمنصة أريد كمنصة بحثية وتعليمية للباحثين الناطقين بالعربية. وبصفة خاصة تهدف هذه الدراسة إلى:

$$
\begin{aligned}
& \text { • رصد نمو عدد الباحثين المشتركين في المنصة خلال السنوات الماضية، والتوزيع الجغر افي لهؤلاء الباحثين. } \\
& \text { • تصنيف الجامعات و المؤسسات الأكاديمية حضورًا على المنصة. } \\
& \text { • رصد الأنشطة الأكاديمية للباحثين المسجلين بالمنصة، وأكثر ها تو اتنرًا عن غبرها. } \\
& \text { • التعرف على اهتمامات الباحثين التخصصية، وأبرز ها حضورًا على المنصة. } \\
& \text { • رصد الثهادات الأكاديمية، و المهارات العلمية، وغيرها من الملامح ذات الصلة لمنصة أريد. } \\
& \text { • توضيح بعض الأنظمة التي ابتكرتها المنصة، مثل نظام منح الأوسمة، ونظام عليم للتعليم الإلكتروني. }
\end{aligned}
$$

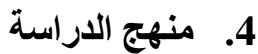

تعتمد هذه الدراسة على المنهج الوصفي التحليلي، وبصفة أساسية على بعض أساليب القياسات الور اقية (اليبليوجر افية) Rehn, Kronman, Gornitzki, Larsson, \& Wadskog, 2008) Bibliometrics و هي تلك الأساليب الكمية التي تُعنى في الأساس بقياس خصائص مصادر المعلومات في أي مجال علمي تخصصي، وتحليلها وتفسير ها، وبيان عناصره الأكثر نشاطًا وإنتاجًا من غير ها. وتهدف اليبليومتريقا، على العموم، إلى تقييم آليات البحث العلمي المتخصص، وتوفير البيانات اللازمة لنتخذي القرار و القائمين على رسم السياسات العلمية في المجتمع (فراج، 2016). وتكثـف مر اجعة الإنتاج الفكري أن الباحثين الذين اهتموا بدر اسـة اتجاهات البحث في الإنتاج الفكري وخصـائصـه، اعتمدوا في الأســاس على اسـتخدام الأسـاليب البليلومترية Bibliometric techniques في تحليل الييانات. كما تكثـف هذه المر اجعة أن هذه الأسـاليب هي أفضـل المناهج المسـتخدمة في هذا النوع من الدراسـات، و الذي يعد مسـتخدماً بكثافة في قياس الإنتاج الفكري في التخصصات الهتنو عة، وبخاصة في العقود الأربعة الأخيرة. و الو اقع أن تلك الأســاليب البليومترية والدراســات التحليلية التي تتبني عليها، طريقة شـائعة لقياس إنتاجية البحوث وخصائصها في التخصصات العلية المتنوعة؛ تلك البحوث الصادرة في هيئة رسائل جامعية (ع. فراج, 2015)، أو المنشورة 
في الدوريات العلمية (Mowafi, 2012)، أو الناتجة عن الأفر اد (Kademani, Kalyane, Kumar, \& Science, 2001) أو المؤسسات أو المجتمعات الأكبر حجماً كالدول والأقاليم الجغر افية على سبيل المثال (Kirby, 1991) وفيما يتصل بالبيانات التي نمّ الاعتماد عليها في هذه الدر اسة، فقد تم استخر اجها من قاعدة بيانات "منصة أُريد" بتاريخ 12 مايو 2021، وتم هنا استخدام التحليلات الإحصائية و البيليومترية الملائمة بما يحقق أهداف الدر اسة، كما تم استخدام برنامج Excel

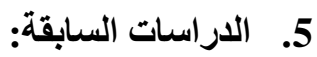

تمثل المنصات العلمية أحد أبرز المنافذ التي يقوم فيها العلماء و الباحثين بإتاحة معلومات عن تخصصاتهم والأنشطة

و المشاريع الجارية و المساهمات الأكاديمية الخاصة بهم (Martín-Martín, Orduña-Malea, \& López-Cózar, 2018). وقد كثفت الدر اسات السابقة التي قامت بدر اسة المو اقع الثخصية للباحثين وجود تنوع كبير في التخصصات و البلدان والأعمار و الأجناس. بالإضافة إلى ذلك، يوجد عدد لا بأس به من الباحثين الذين لديهر مو اقع شخصية خاصة بهم لكنها تفتقر إلى الكثير من Barjak, Li, Thelwall, \& Technology, 2007; ) المعلومات الأساسية التي تتحدث عن طبيعة تخصصاتهم وتفاصيلها .(Mas-Bleda \& Aguillo, 2013; Mas-Bleda, Thelwall, Kousha, \& Aguillo, 2014 فقد بينت نتائج اسنطلاع أجرته مجمو عة Nature Publishing Group أنه يوجد استخدام متز ايد للمنصات الاجتماعية من قبل العلماء و الباحثين (Van Noorden, 2014). وقد حاولت إحدى الدر اسات (Martín-Martín et al., 2018) استكثاف مدى تبني الباحثين في قياسات المعلومات (Google Scholar Citations, ResearcherID, ResearchGate, لبعض أثهر المنصات العلمية والبحثية وهي ،يث أثنارت نتائج هذه الدراسة إلى أن عددًا مهمًا من الباحثين كان لديهم ملف تعريف في Google Scholar Citations وكذلك فإن العديد منهم (67\%) لديهم أيضًا ملف تعريف في ResearchGate ، مما جعله ثاني أكثر المنصات استخدامًا في وقت جمع البيانات. 
كما أن القياسات الناتجة عن هذه المنصات تقع في فئتين رئيستين هما: القياسات الدالة على مدى الارتباطو التفاعل وهي التي تتصب على عدد المتابعين followers، و القياسات الدالة على مدى الإفادة من المعلومات وهي بدور ها تتقسم إلى نمطين؛ يختص أو لاهما بمدى القر اءة و الاطلاع، بينما ينصب الثاني على قياسات الإشار ات المرجعية. كما حاولت در اسة أخرى الكثف عن مدى الإفادة من منصة Google Scholar Citations من قبل الباحثين في مجال المكتبات و المعلومات في باكستان، وتوصلت الدر اسة إلى أن إجمالي حضور هؤ لاء الباحثين لهذه المنصة يعد منخفضًا بصورة نسبية، كما أن هذه النسبة لم تعمل على تعظيم الفرص التي توفر ها المنصة بغرض التألق البحثي و العلمي على الإنترنت .(Ali \& Richardson, 2019)

و اعتمادًا على منصة ResearchGate ، حاولت إحدى الدراسات فحص أحد القياسات الحديثة لهذه المنصة وهي ما تسمى بالاهتمامات البحثية Research Interest. ويعتمد هذا المقياس على وزن الاستشهادات المرجعية، والتوصيات، و عدد قر اءات النصوص الكاملة، و القر اءات الأخرى لأعضاء هذه المنصة (S. J. S. Copiello, 2019). و اعتمادًا على منصة ResearchGate أيضًا، حاولت إحدى الدراسات الكثف عن مدى العلاقة بين عدد النصوص الكاملة المرفو عة لباحث معين على المنصة، ومعدلات قر اعة هذه النصوص، وما يعرف بمؤشر (آر جي) RG Score. و أسفرت الدر اسة عن أن النتائج المستخرجة من مجموعة البيانات محل البحث تؤدي إلى نتائج منضاربة. وهو ما يحتاج إلى مزيد من الدر اسات في هذا المضمار (S. Copiello \& Bonifaci, 2018). ونظر اً لأن المنصة تهدف إلى تأكيد نفسها كثبكة اجتماعية Orduna-Malea, Martín-Martín, ) بكمية ونوعية التفاعلات بين المستخدمين RG علمية رائدة، تتأثر نقاط المؤشر Jamali, ) (Thelwall, \& López-Cózar, 2017 .(Nicholas, \& Herman, 2016 


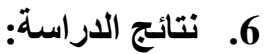

\section{6. التوزيع الجغرافي والزمني لمستخدمي المنصة:}

وفقاً للبيانات التي تم استخر اجها من المنصة بتاريخ 12 مايو 2021، فقد بلغ عدد مستخدمي المنصة (70,000) باحثاً و عالماً وخبير أ من (105) دول حول العالم. ويوضح الثكل (1) نمو عدد المستخدمين خلال السنوات الخس الماضية، ومنه يتضح زيادة عدد هؤلاء المستخدمين بإطر اد من فترة زمنية إلى أخرى. ويعكس هذا النمو في عدد المستخدمين إلى اقبال الباحثين على هذا النوع من المنصات العلمية و اهتمامهم بما تقدمه من نشاطات علمية. أما الثكل (2) فيوضح التوزيع الجغر افي لعدد المسجلين في المنصة وذلك بحسب كل دولة.

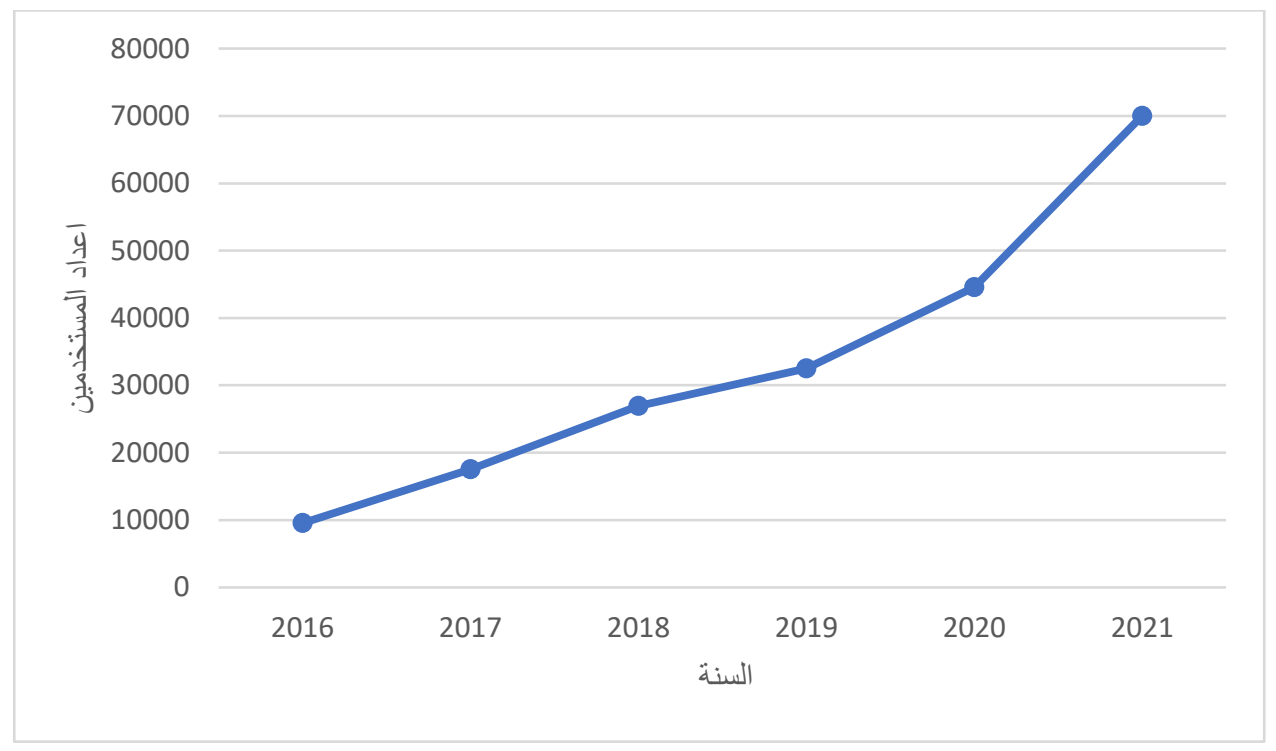

الثكل (1): النمو في عدد المستخدمين للمنصة (2016-2021) 


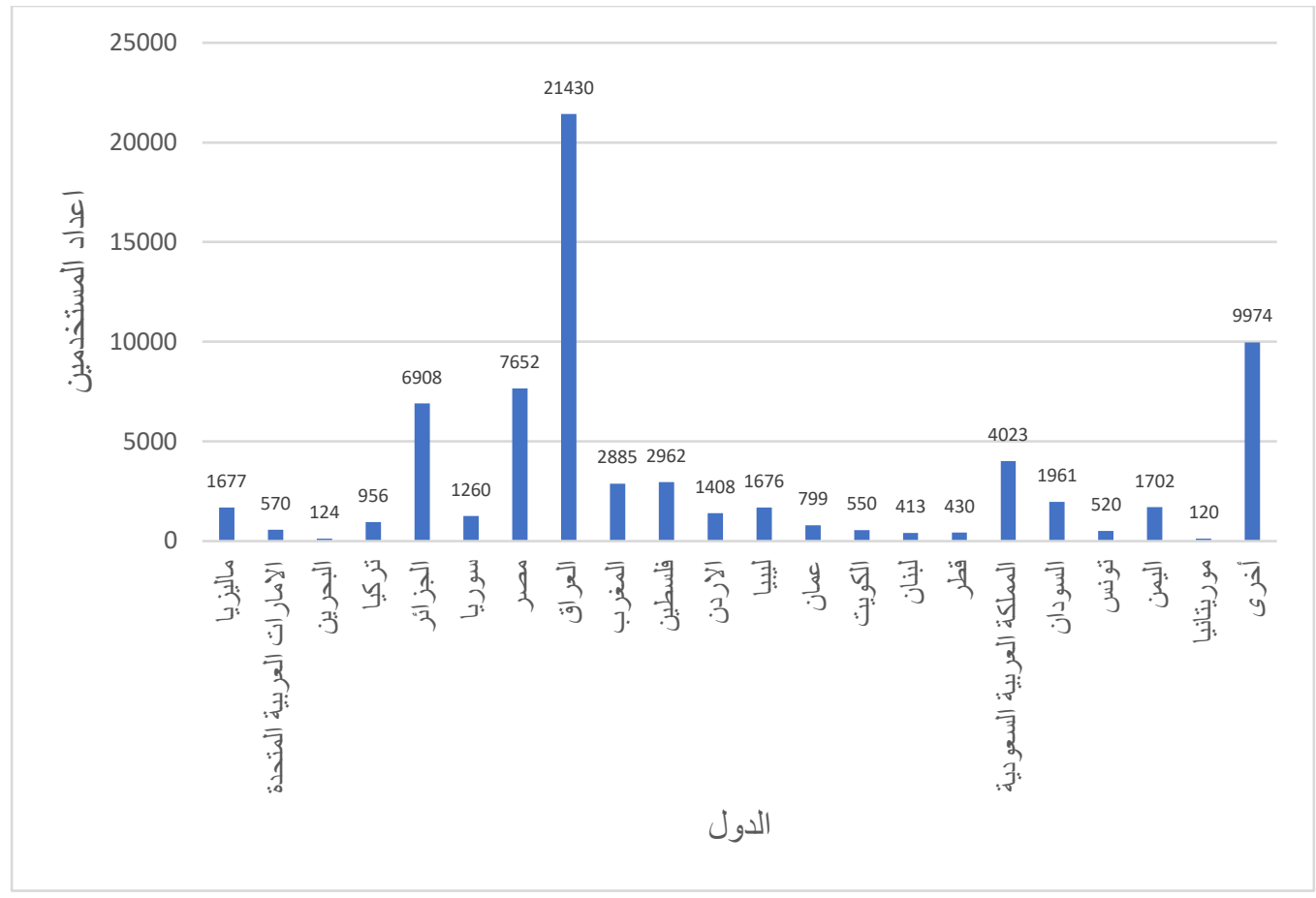

$$
\text { شكل (2) توزيع اعضاء منصة أريد على الدول }
$$

ويلاحظ هنا أن العراق تبوأ المرتبة الأولى في عدد المسلين في المنصة بواقع 21,430 باحثًاً (حوالي 30.6\%) أي ما يقرب من ثلث مجموع الباحثين على المنصة، ويُعزى هذا الارتفاع في أعداد المسجلين في العراق إلى توجيهات وزارة التعليم العالي العر اقية ورؤساء الجامعات بضرورة التسجيل في المنصة والاستفادة من المو اد العلمية والدورات المقامة فيها. بالإضافة إلى ذلك، فقد تم إقامة نسخة من المحفل العلمي السادس فيه (أحد النشاطات العلمية للمنصة)، وكذلك نشاطات و أعمال اللجنة التنسيقية الفرعية في العراق. وتأتي مصر في المرتبة الثانية برصيد 7,652 باحثاً، و يعزى ذلك الى جهود أعضاء المنصة في مصر وتفاعلهم مع نشاطاتها المتنو عة. كما احتلت الجز ائر المرتبة الثالثة، فقد بلغ عدد الأعضاء المسجلين من الجزائر في المنصة 6,908 باحثًا. ولعل أحد أسباب هذه الزيادة هو إقامة نسخة من المحفل العلمي الدولي السادس في الجزائر في شهر أبريل عام 2020، فضلا عن جهود الباحثين الجز ائرين لنهضة بحثية في الآونة الأخيرة كان من ضمنها إنشاء بو ابة المجلات العلمية الجزائرية. 
أما المملكة العربية السعودية فقد كانت في المرتبة الر ابعة بو اقع 4,023 باحثناً، ثم فلسطين في المرتبة الخامسة بواقع 2,962 باحثاً، ويوضح شكل (3) التوزيع الجغر افي للمسجلين في العالم، على اعتبار أن الحد الأدنى هو 120، لكن توجد بعض الدول كان فيها عدد المسجلين أقل من 120 باحثاً كالدول الأوربية و أمريكا وكندا ولم تظهر في الثكل.

$$
\text { الثكل (3): التوزيع الجغر افي للمسجلين في منصة أُريد في العالم لسنة } 2021
$$

7. أبرز الجامعات حضورًا على المنصة:

ينتمي جميع المسجلين في المنصة إلى $(17,736)$ جامعة ومركز بحثي ومؤسسة أكاديمية موزعة على كثير من دول العالم. ويوضح جدول (1) أسماء الجامعات الخمس الأُولى في الدول الخمس الأُولى مع الإشارة إلى عدد المسجلين في كل جامعة. 


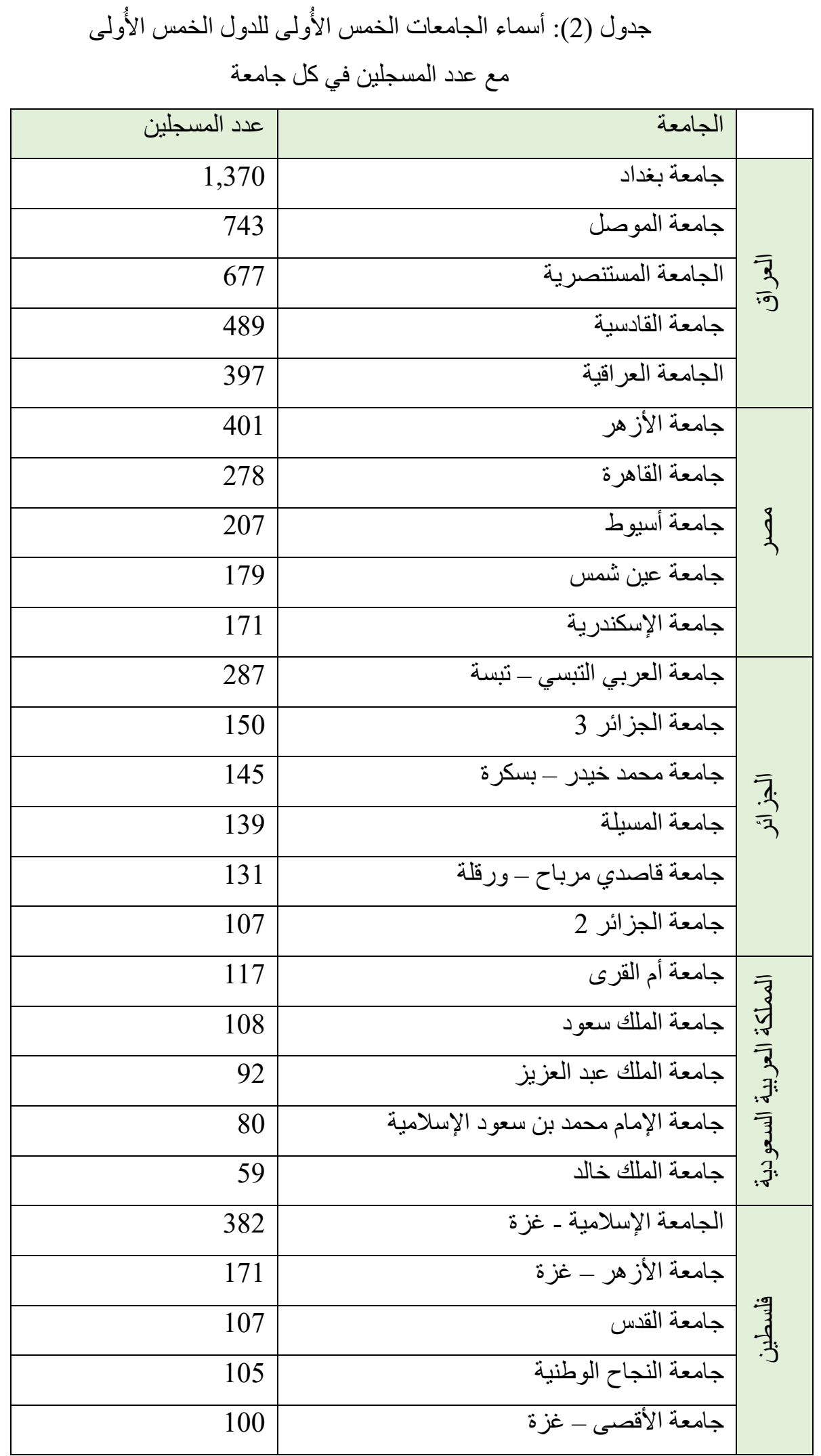


ونلاحظ في جدول (1) أن جامعة بغداد تتصدر الجامعات العر اقية في عدد المسجلين، ثم تأتي جامعة الأز هر على رأس الجامعات الصصرية وهي أحد أعرق الجامعات العربية والإسلامية كما هو معلوم. أما في الجزائر، فتتصدر جامعة العربي التبسي - تبسة الجامعات الأخرى في عدد المسجلين في المنصة وربما كان السبب أن هذه الجامعة كانت أحد الرعاة للمحفل العلمي الدولي الساد. وتحتل جامعة أم القرى المرتبة الأولى في المملكة العربية السعودية وهي إحدى أبرز الجامعات العربية، و أخير اً تحتل الجامعة الإسلامية - غزة المرتبة الأُولى بين الجامعات في فلسطين، وهي و احدة من أنشط الجامعات العربية بالر غم مما يمر به قطاع غزة من ظروف ضاغطة يعرفها الجميع.

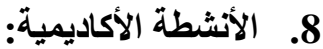

تضمنت الأنثطة الأكاديمية الموجودة في المنصة (36) نوعاً من ضمنها تأليف الكتب أو كتابة فصول من كتب و المشاركة في المؤتمر ات وغيرها. أما الدخخلات المسجلة من قِبل أعضاء المنصة فقد بلغت $(39,277)$ مدخلاً.

$$
\text { ويوضح الثكل (4) أعداد اليُدخلات لأعلى (15) نشاطا أكاديمياً. }
$$

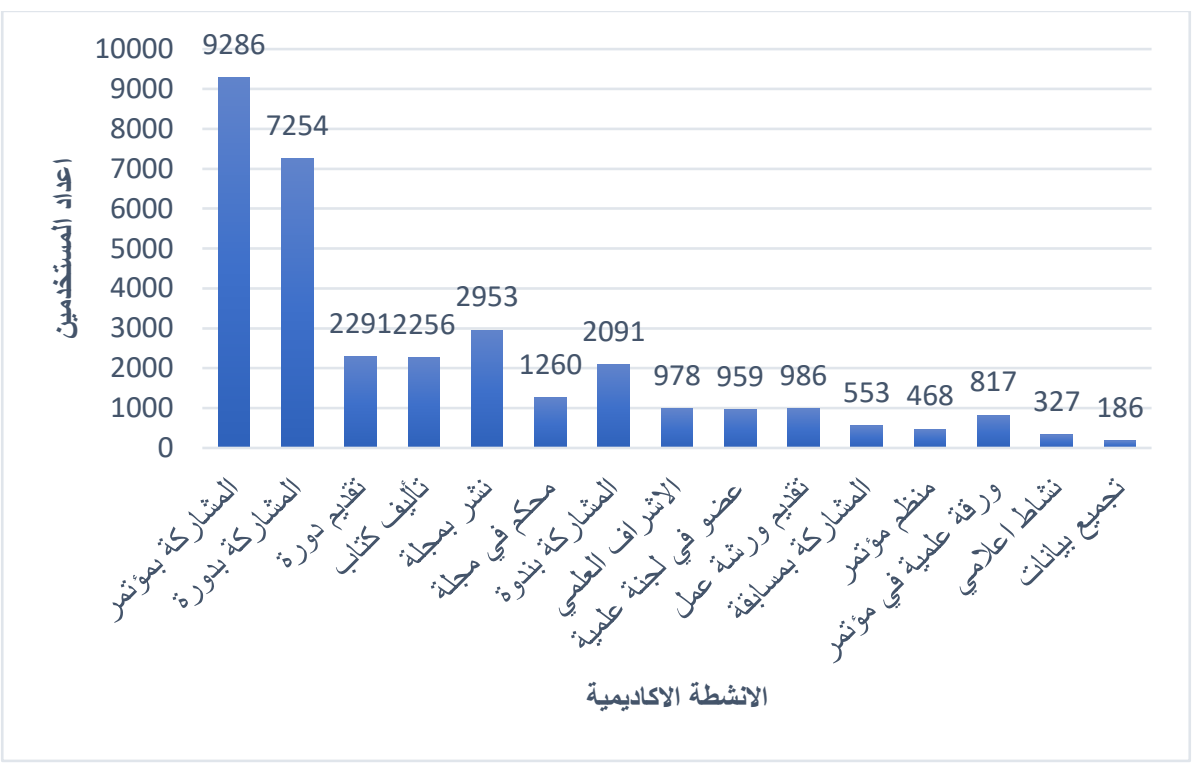

الثكل (4): أعداد المُدخلات لأبرز (15) نثاطاً أكاديمياً. 
ووفقاً للثكل (4)، يمكن ملاحظة أن المشاركة في المؤتمرات تتصدر جميع الأنشطة الأكاديمية (9,286)، تليها المشاركة في الدور ات العلمية (7,254)، ومن المُرجح أن السبب في ذلك هو سهولة المشاركة في هذا النوع من الأنثطة مقارنة بغيره. بالإضافة إلى ذلك، يُلاحظ أن ارتفاع عدد الدخلات في مجالي تقيم الدورات (2,291) وتأليف الكتب (2,256) و هذا يعكس قدرة الباحث العربي على تقديم الدور ات العلمية و إقباله على الإبداع الفكري وقدرته على التأليف

$$
\text { و الكتابة. }
$$

و الحقيقة أن إقامة المؤتمرات هي أحد أبرز الأنشطة العلمية والبحثية التي تقدمها (أريد)، وذلك استجابة للاحتباجات العلمية والبحثية للعالم العربي؛ وبصفة خاصة في العام المنصرم الذي شهد جائحة كو فيد-19 وما استتعها من إجر اءات حدت من إعداد الملتقيات العلمية بصورة مباشرة وتحول العالم كله إلى المؤتمر ات و الفعاليات الافتر اضية وهو ما كانت

$$
\text { (أريد) حاضرة فيه بصورة قوية وملموسة. }
$$

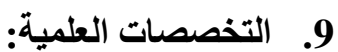

ومن حيث التخصصات العلمية التي وسمت الاهتمامات الموضو عية للباحثين، فقد بلغ عدد اليُدخلات فيها (20,080) تخصصاً. ويوضح شكل (5) التخصصات العلمية ونصيب كل منها في المنصة. 


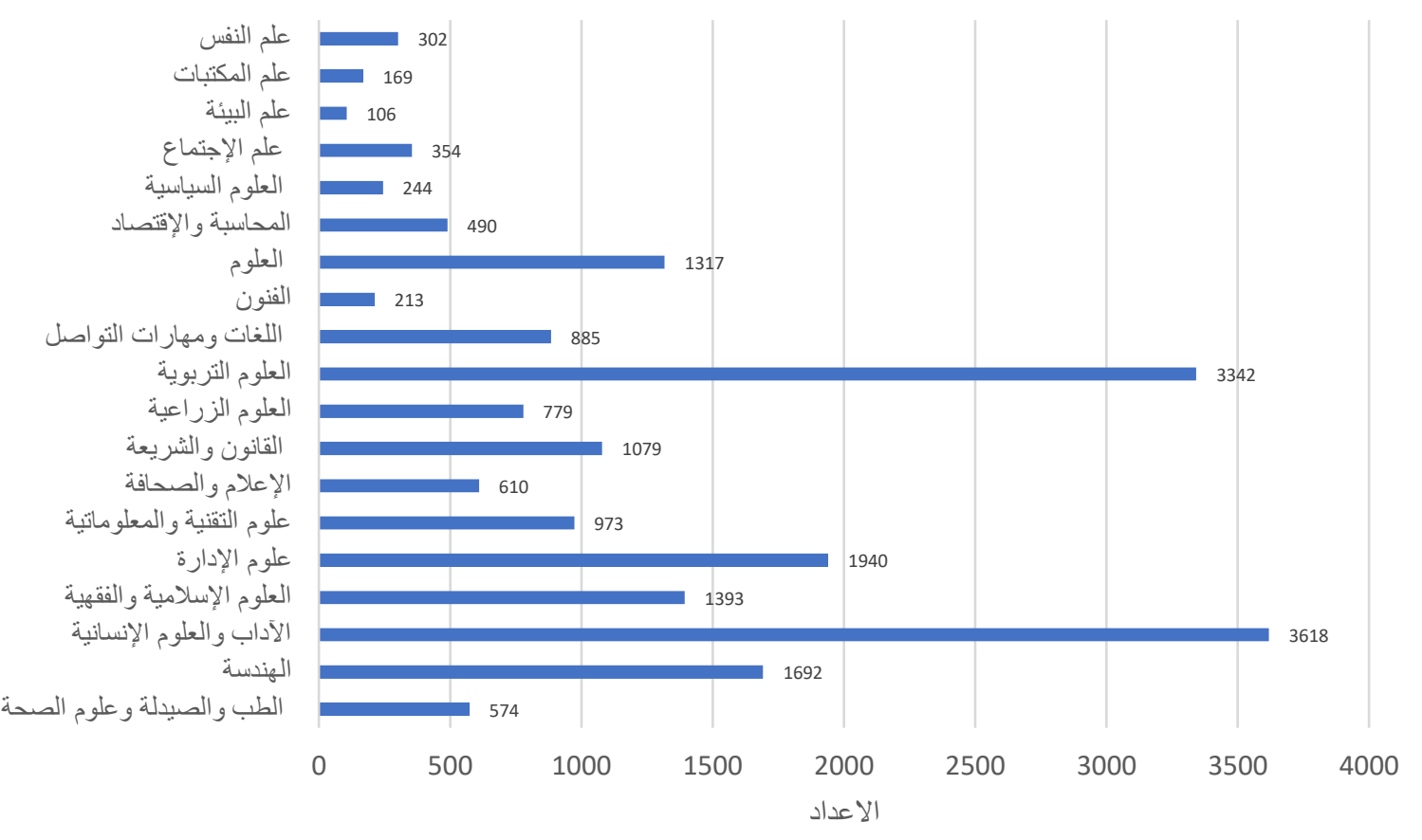

\section{الثكل (5): التخصصات الموضو عيةو أعدادها في المنصة}

وكما هو و اضح، هناك تداخل بين بعض التخصصات الموضو عية، كما أن بعضها عريض للغاية مثل الآداب و العلوم الإنسانية، وبعضها دقيق للغاية مثل علم البيئة. ويعكس ذلك سلوكيات الباحثين في وسم المصطلحات الدالة على تخصصاتهم الموضو عية.

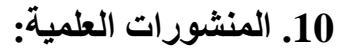

تنبغي الإشارة هنا إلى أنه يوجد قسم مستقل للمنشور ات العلمية يُحسب بشكل مستقل عن الأنشطة العلمية. وقد بلغ عدد المنشور ات العلمية (16,669) مادة. ويوضح الثكل (6) توزيع المنشور ات العلمية في كل نمط من أنماط مصادر المعلومات. 


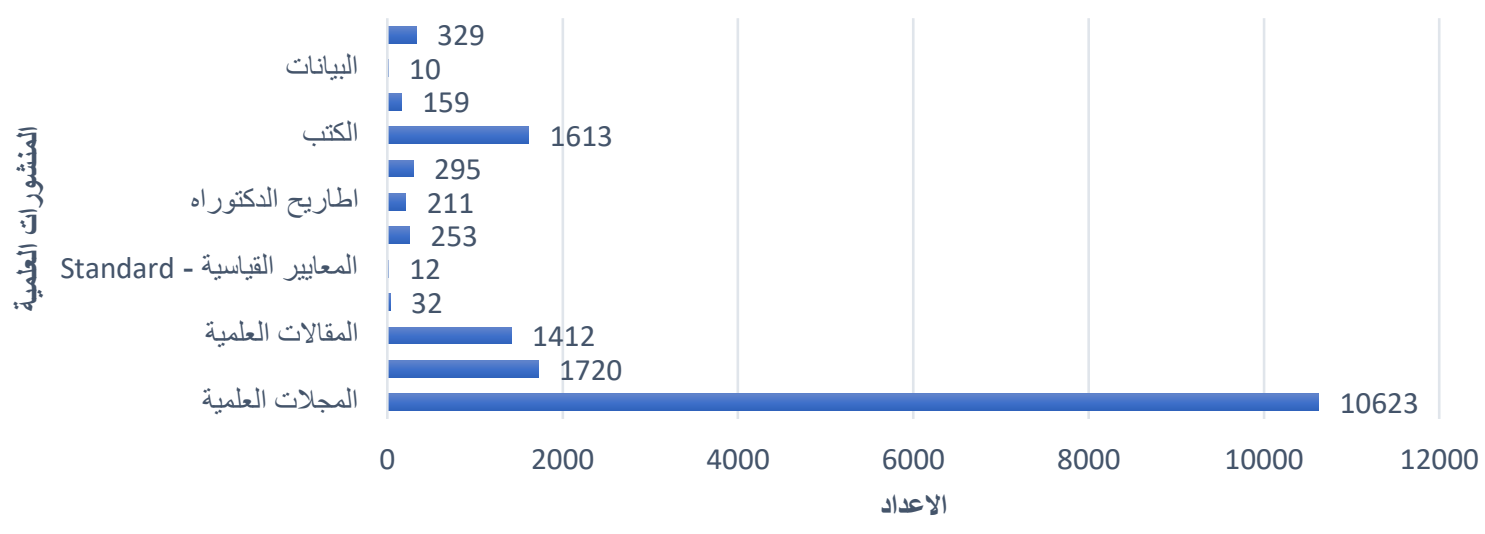

$$
\text { الثكل (6): المنشور ات العلمية و أعدادها }
$$

ونلاحظ أن أغلب المنشور ات كانت في المجلات العلمية والتي بلغ عددها (10,623) بحوث، وذلك بنسبة تتجاوز نصف عدد المنشور ات جميعًا (حو الي 63.7\%). و هذا شيء طبيعي في ضوء أن الدورية العلمية هي القناة الرئيسة للاتصسال العلمي في كثير من تخصصات المعرفة البشرية. وتأتي المؤتمرات في المرتبة الثانية بين أنماط مصادر المعلومات برصيد $(1,720)$ بحثاً، تليها الكتب برصيد 1,613 كتاباً ثم المقالات العلمية (1,412) مقالة. وهذه في الحقيقة هي بعض أبرز أنماط مصادر المعلومات في العالم المعاصر الذي نعيش فيه. وتمثل بقية أنماط مصادر المعلومات أقل من 8\% من مجموع المنشورات المثبتة على المنصة، وإن كان من بينها ما يمثل أهمية بالغة في النشاط العلمي وبصفة خاصة في العلوم و التقنية مثل التقارير وبر اءات الاختر اع والمعايير القياسية. ولا يمكن تفسير هذه النتيجة سوى ضعف النشاط العلمي العربي في هذه الأنماط بصفة عامة، أو ضعف الصادر من هذه الأنماط لدى الباحثين المسجلين في المنصة.

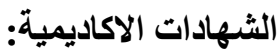

يوضح شكل (7) عدد المُدخلات لكل شهادة اكاديمية، ومنه يتضح أن عدد المُدخلات عن الثهادات الأكاديمية (18,612)، منها (6,112) مُدخلاً لشهادة الماجستير بنسبة حوالي ثلث مجموع الثهادات (30.6\%)، و(5,486) مُدخلاً لثهادة الدكتور اه. أما شهادة البكلوريوس فقد بلغ عدد المُدخلات فيها (4,801) مدخلاً. 


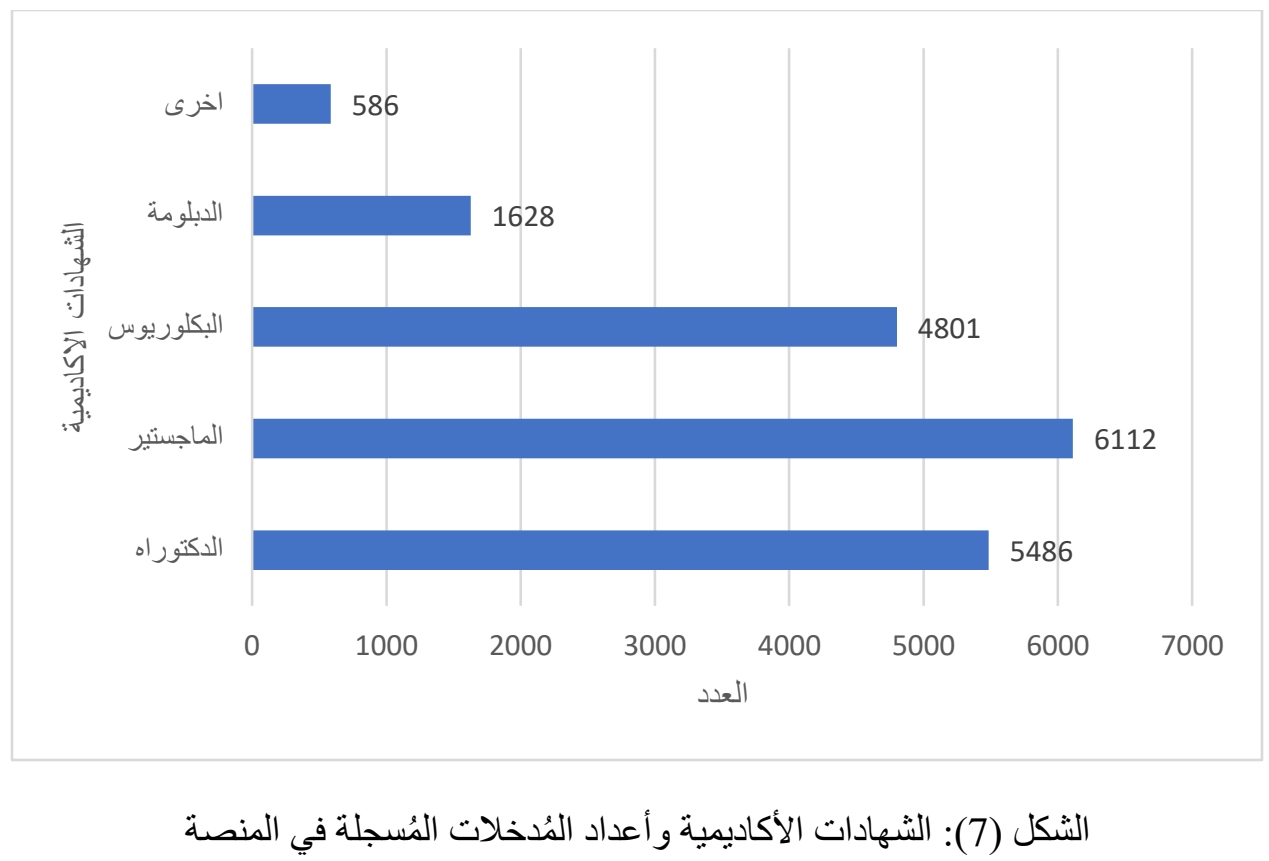

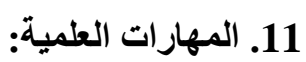

بلغ عدد المهار ات المسجلة في "منصة أريد" 1,143 مهارة، حيث يوضح هذا العدد الغزير ثراء الجدارات العلمية و البحثية للباحثين المسجلين بالمنصة، ومن هذه المهار ات: البحث العلمي، و الكتابة الأكاديمية، و التدقيق اللغوي، وإدارة المشاريع، و إدخال البيانات، وغير ها. وقد بلغ مجموع سجل المهارات التي أُدخلت في المنصة (27,775) مدخلاً. ويوضح شكل (8) عدد المُدخلات المسجلة لأبرز خمس مهار ات علمية.

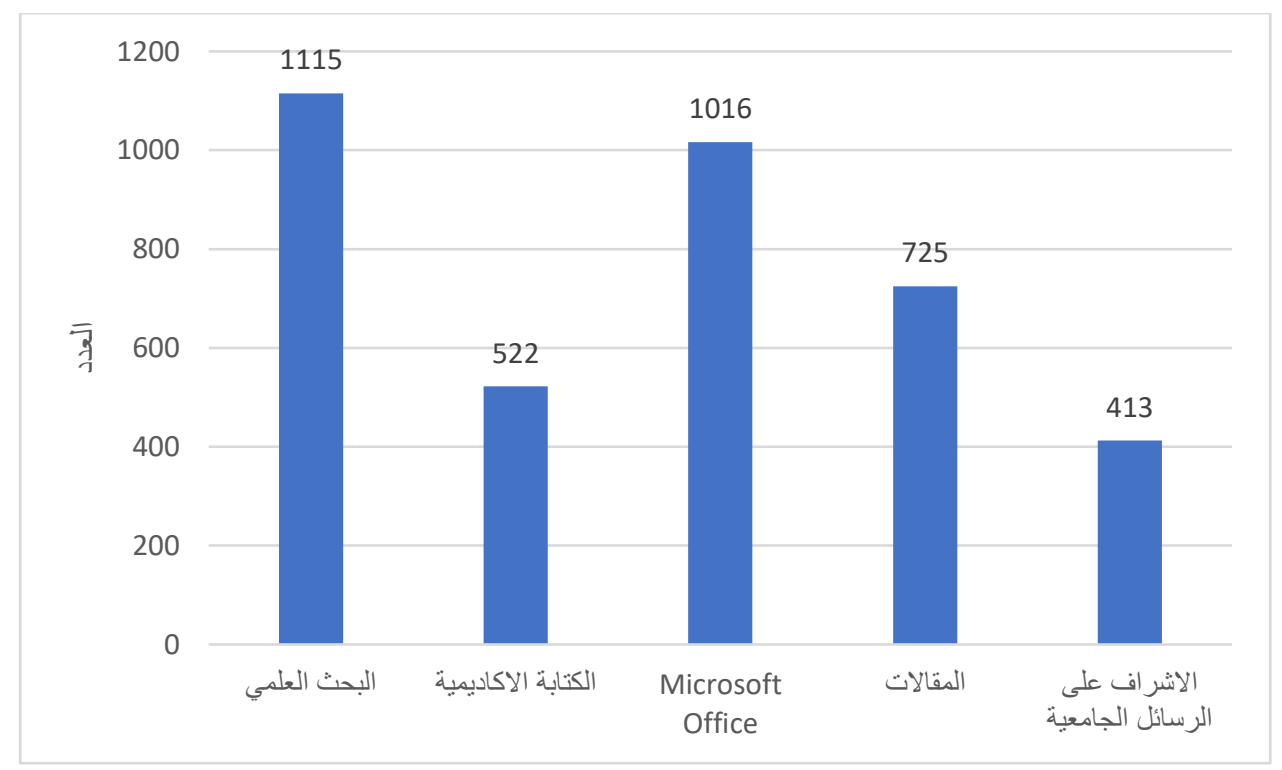


ARID International Journal of Informetrics and Scholarly Communication (AIJISC) VOL: 2, NO 3, July 2021

الثكل (8): المهار ات العلمية وأعداد المُدخلات المسجلة في كل مهارة.

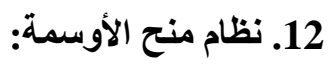

توفر المنصة 20 نو عاً من الأوسمة، تُنح للباحثين كنوع من التشجيع و التكريم بحسب التفاصيل الموضحة في المنصة. وقد بلغ عدد الباحثين الذين حصلوا على الأوسمة (10,679) باحثاً، ويبين الجدول (7) أنواع الأوسمة وأعداد الباحثين الذين حصلو ا على كل وسام. وقد تم استحداث وسام مقدم خدمات بحثية ووسام عالم ووسام المسؤولية المجتمعية ووسام القيادة العلمية مؤخر اً، ويعتبر عدد الحاصلين على هذه الأوسمة الحديثة قليل نسبياً من ناريخ استخر اج البيانات.

جدول (7) أنو اع الأوسمة المقدمة من المنصة ورصيد الباحثين الحاصلين عليها

\begin{tabular}{|c|c|}
\hline عدد الباحثين الحاصلين على الوسـام & نوع الوسام \\
\hline 4067 & وسام باحث مبادر \\
\hline 93 & وسام ناشِط في جامعة \\
\hline 292 & وسام مُبْدِع \\
\hline 30 & وسام ناشِط دوليّ \\
\hline 13 & وسام إعلامي متميز \\
\hline 55 & مُحكّم \\
\hline 19 & و سـام مُستشَّار \\
\hline 37 & وسام دَاعِم فضي \\
\hline 96 & وسام نَاثِرِ مُتميّزِ \\
\hline 285 & وسام الصفحة المتميزة \\
\hline 126 & وسام "مشروع عالم" \\
\hline 420 & ناثط في فعاليات منصة اريد العلمية \\
\hline 136 & باحث مبتدئ \\
\hline 6 & وسام التحدي \\
\hline 2978 & ناشط في فعاليات منصة اريد العلمية لسنة 2020 \\
\hline 1 & مقدم خدمات بحثية \\
\hline 1988 & وسام الصفحة المتميزة للعام 2020 \\
\hline
\end{tabular}




\begin{tabular}{|c|c|}
\hline 5 & وسام عالِم \\
\hline 2 & وسام المسؤلية المجتمعية \\
\hline 30 & وسام القيادة العلمية \\
\hline 10,679 & المجموعة \\
\hline
\end{tabular}

13. نظام عليم للتعليم الأكتروني:

تم استحداث نظام جديد داخل المنصة أُطلق عليه "نظام عليم" بتاريخ 1 مارس 2020 مع بدء انتشار جائحة كورونا وما ر افقها من حظر صحي وأغلاق للمؤسسات التعليمية، وقد تم رفع الدورات والمحاضرات التعليمية وإصدار الثهادات الخاصةة بها على هذا النظام لِدعم التعليم عن بُعد للناطقين باللغة العربية. وقد بلغ عدد المحاضر ات في "نظام عليم" 265 محاضرة، سجل فيها $(86,007)$ مستخدماً، أما عدد الثهادات المصدرة منذ تاريخ إفتتاح النظام لحد الآن فهي (41,022) شهادة. في حين بلغ عدد المحاضر ات في دراسة تم نشر ها العام الماضي 58 محاضرة، سجل فيها (659,16) مستخدماً، أما عدد الثهادات المصدرة فقد كانت (222,8) شهادة (م. ق. س. ا. ع. فر اج, 2020). هذه الزيادة الكبيرة في المحاضرات (اربع اضعاف تقريباً) تدل على أن اهتمام المنصة بتطوير هذا النظام، وكذلك اهتمام المتعلمين و الإقبال على هذا النوع من أساليب التعليم.

\section{4. ملامح إحصائية أخرى لمنصة أريد:}

إضافة إلى ما سبق من سمات وخصائص "منصة أُريد"، نود الإشارة إلى أن عدد السبر الذاتية المرفو عة على المنصة بلغ 15,507 سيرة ذاتية. كما بلغ عدد البحوث المقدمة إلى المحفل العلمي الدولي بنسخِه السبع (1,238) بحثناً في المجالات العلمية المتتو عة. أما البحوث المقدمة إلى مجلات منصة أُريد الخمسة المحكّة فقد بلغ عددها (505) بحوث

$$
\text { في حين أن عدد البحوث التي اجيزت للنشر (167) بحثاً اي أن نسبة القبول 33\%. }
$$

وبلغ عدد المشاريع البحثية المضافة للمنصة (2,322) مشرو عاً، في حين بلغ عدد الخبرات التنريسية المضافة للمنصة (7,667) خبرة. و أما ما يتعلق بعدد المتابعات (Follows) بين الأعضاء في منصة أريد فقد بلغ (28,469) متابعة. كما يُلاحظ وجود زيادة كبيرة وملحوظة في عدد المدونات حيث بلغ عدد المدونات العلمية (7,482) مدونة، كما بلغ 
مجموع القراءات للمدونات 847,901 قراءة حسب البيانات التي تم استخر اجها بتاريخ 12 مايو 2021 م، في حين كانت 2,100 مدونة في العام الماضي حسب در اسة سابقة (م. ق. س. ا. ع. فر اج, 2020). و نُعزى هذه الزيادة إلى المسابقات التحفيزية التي تقيمها منصة أُريد للمشتركين حيث تقوم كل شهر باختيار أفضل 3 مدونات وتكريم الفائزين مما شجع الباحثين على الكتابة والنشر في مدوناتهم. كما بلغ عدد الزيار ات لصفحات الأعضاء 22,502,412. أما عدد روابط الصفحات الثخصية لمواقع التواصل الاجتماعي التي أضافها الباحثون إلى صفحاتهم في المنصة ــ كروابط صفحات الفيسبوك و الباحث العلمي لجوجل و غير ها ـ فقد بلغ (1,620) رابط. وفي حين كانت ثقافة المجمو عات البحثية و التعاون العلمي المشترك كانت بنسبة ضعيفة جداً لغاية العام الماضي بحسب نتائج در اسة سابقة (قيس وآخرون، 2020)، وقد أوصى الباحثون بضرورة الالتفات لنشكيل مثل هذه المجموعات و أهميتها في مجال البحث العلمي. و عليه فقد نمّ الأخذ بتلك التوصية والإعلان عن بدء تشكيل المجموعات البحثية في المحفل الدولي السابع في نوفمبر 2020. وقد بلغ عدد المجموعات البحثية لحد الأن خمس مجموعات. ويقصد بالمجمو عات البحثية "مجموعات تُعنَى بالعمل البحثي المشترك بين عددٍ من الباحثين، من أجل إنجاز أبحاث متميّزة كماً ونو عاً وذات فائدة للمجتم، وتتكون المجمو عة البحثية من مجمو عة من الباحثين من تخصصات متنوعة ومتكاملة و إمكانات وخبرات بحثية، تضمن الجودة وكثافة الإنتاج، إلى جانب باحثين ناشُئين، وطلاب در اسات عليا؛ لإكسابهر المهار ات البحثية، و التمرُّ" (المجموعات البحثبة، 2020). بالإضافة إلى ما سبق، فيلاحظ أن هناك زيادة في عدد إصدار ات المنصة حيث لم يكن للمنصة أي اصدار خلال العام الأول من التأسيس 2016 في حين أن الإصدار ات لسنة 2021 بلغت 12 مؤلفا، حيث يُعزى السبب في ذلك إلى تشجيع المنصة الباحثين على التأليف و النشر . أما مجلة صدى أُريد و التي تم اطلاقها في 15 مايو 2020، تم إصدار 12 عددا منها بو اقع عدد واحد في الثهر وقد بلغ مجموع أعداد

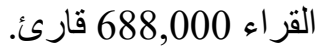

هدفت هذه الدراسة إلى إلقاء الضوء على أنشطة منصة أُريد في السنوات الخمس الأولى من إنشائها (أي بين عامي 2021-2016)، وبعض ملامحها وخصائصها البنيانية، ودلالات ذللك بالنسبة للاتصال العلمي في المجنمع العربي. 
ويمكن القول إن أعداد المستخدمين في "منصة أُريد" في تز ايد مستمر، وهو ما يدل على أهمية دور ها الذي أنشئت من أجله، كما يدل على حاجة المجتمع العلمي العربي لمثل هذه المنصات البحثية الناطقة بالعربية. وكثفت النتائج أن العراق يتبوأ المرتبة الأولى في أعداد المسجلين في المنصة، وأن جامعة بغداد ـ من بين أبرز الجامعات العر اقية ــ تتبوأ الصدارة في أعداد المسجلين، ويعزى ذلك إلى تشجيع وزارة التعليم العالي والبحث العلمي ورؤساء الجامعات الأكاديميين في العر اق على التسجيل في المنصة وفاعلية اللجنة التنسيقية. وتتصدر المشاركة في المؤتمرات قائمة الأنشطة الأكاديمية، حيث تجاوز عدد الباحثين فيها تسعة آلاف باحث، كما تجمع المنصة طيفًا واسعاً من التخصصات المتنوعة، ويميل أكثر ها إلى العلوم الاجتماعية، كما أن بعض التخصصات تجاوز أعداد المسجلين فيها (2,000) باحث مثل الآداب و العلوم الإنسانية و العلوم التربوية. وقد لعبت (أُريد) دور اً مهمًا في العام المنصرم الذي شهد أحد أبرز الجوائح والازمات الصحية وهي كوفيد-19، وما تبع ذلك من إجر اءات احترازية وتباعد اجتماعي وتحول الملتقيات العلمية في معظم أنحاء العالم إلى الصيغة الافتر اضية بصورة كاملة تقريباً. بالإضافة الى ذللى، فقد تجاوز عدد المنشور ات العلمية الموجودة في منصة أُريد (16) ألف منشور، و هو عدد كبير ويعد نقطة جذب للباحثين والدارسين في المجالات المتنوعة كمصادر لدراساتهم، وكان النصيب الأكبر للمقالات المنشورة في المجلات العلمية حيث تجاوز عددها عشرة آلاف مقالة؛ وهو شيء طبيعي في ظل أن المجلات أو الدوريات العلمية هي المحرك الرئيس للاتصال العلمي في معظم تخصصات المعرفة البشرية.

وتضم المنصة كماً كبير اً من حملة الثهادات العليا (الماجستير والدكتور اه)، حيث تجاوز عددهم (11) ألف باحث، وهو شيء طبيعي في ظل أن المنصة في الأساس تعد منصة بحثية. أما بالنسبة للمهار ات العلمية فقد تصدرت مهارة البحث العلمي القائمة. و على صعيد التعليم الإلكتروني في المنصة، يعد نظام التعليم الأكتروني "عليم" إنجاز اً مهماً حيث استطاع أكثر من (86) ألف متدرب حضور المحاضر ات الموجودة في النظام خلال مدة سنة من تاريخ انطلاق النظام، وبصفة خاصة في ظل ظاهرة التباعد الاجتماعي الناتجة عن انتشار فيروس كورونا المستجد في أرجاء العالم.

وبالر غم من جميع هذه الإنجاز ات الكبيرة للمنصة إلا أن أعداد المسجلين في بعض التخصصات يعد قليلاً، لذلك يوصي الباحثون بضرورة استهداف منتسبي هذه التخصصات وتشجيعهم على الإنضمام إلى المنصة ومشاركة نشاطاتهم 
ARID International Journal of Informetrics and Scholarly Communication (AIJISC) VOL: 2, NO 3, July 2021

العلمية. كما أن عدد المسجلين في بعض الدول العربية يعد قليلاً، لذلك يُوصى بضرورة نشر ثقافة الانضمام إلى المنصة بين الباحثين في هذه الدول. بالإضافة إلى ذلك، يوصي الباحثون بدمج الأنشطة العلمية مع المنشور ات لتكون المنشور ات جزءاً من الأنشطة العلمية للحصول على نتائج أكثر دقة. 
منصة أُريد (2021). موسو عة منصة أُريد للكفاءات العلمية الناطقة بالعربية وفقاً لمعامل التواصل العلمي. العر اقي, ر. م. ح., العتيبي, ن. س. م., العصيمي, س. م. ن. (2021). المنصات التعليمية الإلكترونية في الجامعات السعودية

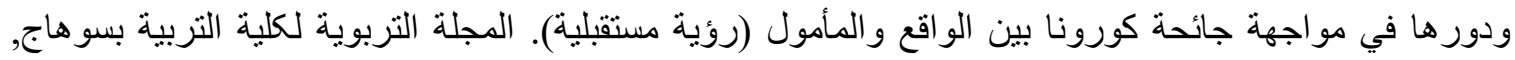

$$
\text { 1050-987, (3) } 86
$$

https://dsrs.ksu.edu.sa/ar/researchgroups المجمو عات البحثية. (2020). جامعة الملك سعود، عمادة البحث العلمي تاجيو, س. ج. (2000). قياسات المعلومات/ ترجمة عبدالرحمن فراج. مج2، ع1 (يوليو 2000). عالم المعلومات والمكتبات

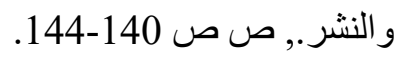

جادالله, ب. س. ص. (2021). تصور مقترح لمعايير جودة المنصات الالكترونية التعليمية فى ضوء بعض النماذج العالمية. مجلة كلية التربية، جامعة بني سويف, 18 (102), 475-52025.

جبور, ع. س. (2020). التعليم الإلكتروني كمدخل لإصلاح قطاع التعليم العالي والبحث العلمي بالجز ائر . مجلة رؤى في الآداب و العلوم الانسانية, 1.

سلمان, ع. م. (2019). التحديات الجيوفيزيائية والاجتماعية و الانسانية والطبيعية في بيئة متغيرة. المؤتمر العلمي الدولي العانشر.

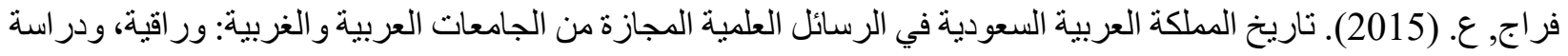
تحليلية الرياض: جامعة إلمام محمد بن سعود الإلسالمية، كرسي الثيخ عبدالعزيز التويجري للار استات الانسانية, 335. فراج, ع. (2016). قياسات المعلومات في مطلع القرن الحادي والعشرين. مؤتمر الدولي لقياسات المعلومات ومعامل الثأثير العربي، الاسكندرية: الاكاديمية العربية للعلوم والتكنولوجيا والنقل البحري، ودار العلوم الطبيعية للنشر الدولي. فراج, ع. (2017). الوصول الحر للمعلومات: طريق المستقبل في الأرشفة والنشر العلمي. مجلة مكتبة الملك فهد الوطنية.

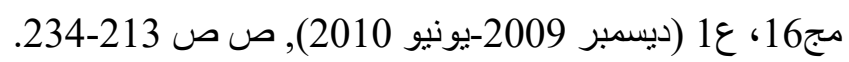

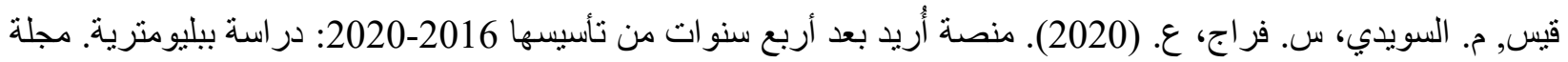

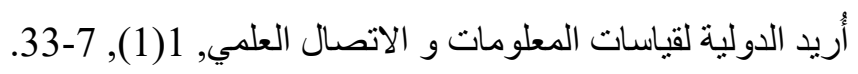

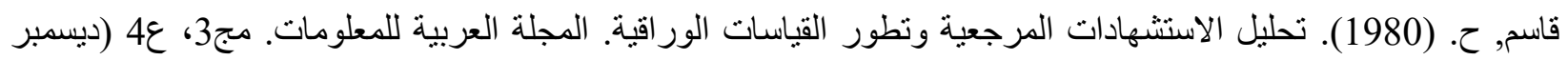

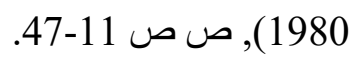

https://arid.my ماهي منصة اريد. (2016) محمد, ع. ا. م. ش. (2019). بناء منصة تعليمية تفاعلية مبتكرة على شبكة الإنترنت. المؤتمر الدولي السابع للتطبيقات الإسلامية

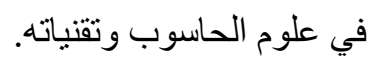

Ali, M. Y., \& Richardson, J. (2019). Google Scholar Citation metrics of Pakistani LIS scholars: an overview. Global Knowledge, Memory Communication, 68( 4/5), 392-412. doi:https://doi.org/10.1108/GKMC-03-2018-0025 
Barjak, F., Li, X., Thelwall, M. J. J. o .t. A. S. f. I. S., \& Technology. (2007). Which factors explain the Web impact of scientists' personal homepages? , 58(2), 200-211.

Copiello, S., \& Bonifaci, P. J. S. (2018). A few remarks on ResearchGate score and academic reputation. 114(1), 301-306 .

Copiello, S. J. S. (2019). Research Interest: another undisclosed (and redundant) algorithm by ResearchGate. 120(1), 351-360 .

Ebrahimy, S., Mehrad, J., Setareh, F., \& Hosseinchari, M. (2016). Path analysis of the relationship between visibility and citation: the mediating roles of save, discussion, and recommendation metrics. Scientometrics, 109(3), 1497-1510 .

Jamali, H. R., Nicholas, D., \& Herman, E. J. R. e. (2016). Scholarly reputation in the digital age and the role of emerging platforms and mechanisms. 25(1), 37-49 .

Kademani, B., Kalyane, V., Kumar, V. J. M. J. o. L., \& Science, I. (2001). Scientometric portrait of Nobel laureate Ahmed Hassan Zewail. 6(2), 53-70 .

Kirby, S. R. J. C. b. (1991). Reviewing United States history monographs: a bibliometric survey .

Martín-Martín, A., Orduña-Malea, E., \& López-Cózar, E. D. J. J. o. i. (2018). Author-level metrics in the new academic profile platforms: The online behaviour of the Bibliometrics community. 12(2), 494-509 .

Mas-Bleda, A., \& Aguillo, I. F. J .S. (2013). Can a personal website be useful as an information source to assess individual scientists? The case of European highly cited researchers. 96(1), 51-67.

Mas-Bleda, A., Thelwall, M., Kousha, K., \& Aguillo, I. F. J. S. (2014). Do highly cited researchers successfully use the social web? , 101(1), 337-356 .

Mowafi, H. A. J. S. j. o. a. (2012). Bibliometric analysis of the volume and visibility of Saudi publications in leading anesthesia journals. 6(4), 393 .

Orduna-Malea, E., Martín-Martín, A ,.Thelwall, M., \& López-Cózar, E. D. J. S. (2017). Do ResearchGate Scores create ghost academic reputations? , 112(1), 443-460 .

Rehn, C., Kronman, U., Gornitzki, C., Larsson, A., \& Wadskog, D. (2008). Bibliometric handbook for Karolinska Institutet. Huddinge: Karolinska Institutet .

Van Noorden, R. (2014). Online collaboration: Scientists and the social network. Nature news, 512(7513), 126 . 